\title{
ASSESSING THE HEALTH OF THE INDUSTRIAL WORKER*
}

\author{
BY \\ R. S. F. SCHILLING \\ From the Rockefeller Unit of Occupational Health, London School of Hygiene and Tropical Medicine
}

In assessing the influence of an occupation on health, the main criterion must be disease, for it is measurable whereas " health" so far defies reliable measurement. The association between disease and occupation is easily observed when the clinical picture is clear as in lead poisoning or silicosis; but sometimes it is so obscure that it is only recognized by a man with a sharp and experienced mind. Sir Thomas Legge (1934), when told of two fatal cases of tetanus among Dundee jute workers, remembered that the Solomon Islanders poisoned their spears by dipping them into mud which was a culture of tetanus bacillus. It occurred to him that the alluvial soil of Bengal in which the jute was grown might be rich in the spores of tetanus bacilli which were then brought to Dundee on the jute fibres. His hypothesis was confirmed.

The relatively simple association of cause and effect in much industrial disease and injury led inevitably to a narrow concept of industrial medicine. But today the industrial medical officer and research worker in addition to investigating ways of preventing clear-cut occupational hazards are expected to determine the extent to which many physical and psychological factors at work may be related to illness. Indeed every doctor in charge of patients is faced with this sort of question: Is the foreman's duodenal ulcer caused or aggravated by his work ? Has the dust from the metal grinder's work been the main cause of his chronic bronchitis ? Has stress played a part in the aetiology of the business executive's coronary heart disease ? These questions are extraordinarily difficult to answer. Yet, as doctors, we often accept too readily that work causes or aggravates disease and restrict our patients unnecessarily, often to their detriment (Melville Arnott, 1955).

Doctors in hospital and in general practice have

* The Mackenzie Industrial Health Lecture of the British Medical Association delivered on September 25, 1956, at B.M.A. House during the 21st anniversary meeting of the Association of Industrial Medical Officers. that most cherished responsibility of looking after individual patients. Those in industrial medicine have less responsibility for individuals but have opportunities, denied to their colleagues in hospital and general practice, to study the distribution of disease in groups of people. By using the methods of epidemiology and looking at groups of workers, it is possible to get information which, even if it does not answer all the questions about the occupational causes of disease, may at least show that work is not always harmful and guide doctors in their care of individual patients. In this way Doll and Avery Jones (1951) in an epidemiological study of the prevalence of peptic ulcer in some 6,000 workers discredited the commonly held views that drivers of motor vehicles are especially susceptible to peptic ulcer and that irregular shifts predispose workmen to this disease.

Observing the patterns of disease in groups of people may be the only way of detecting some occupational hazards and of assessing their influence on health. It is a method which has been applied extensively to occupational mortality and morbidity data and is being used increasingly in clinical studies of groups of workers.

\section{Occupational Mortality}

The Registrar General (1855) first published occupational mortality rates for the year 1851 . As the mouthpiece of William Farr, he wrote: "Laudable attempts have been made by ingenious men to determine the effects of profession on health by general observation unaided by exact recorded facts. Ramazzini and Thackrah in this way deduced some useful practical results and rules for improvement of the health of artizans." But Farr was clearly disturbed by sources of error in his own figures and concluded that occupational mortality statistics could only indicate the direction of further enquiry. At the same time, a remarkably versatile epidemiologist, Dr. Edward Greenhow (1859), was using the Registrar General's data to compile a vast range of 
mortality rates for the inhabitants of certain counties and districts of England and Wales. He wanted facts for teaching sanitary science to the students of St. Thomas's Hospital-an example to the teachers of social and industrial medicine today ! Greenhow found that the death rates for pulmonary disease in men ranged from 221 to 1,440 per 100,000 in different districts. He compared the rates of the lead mining districts of Alston in Cumberland and of Reeth in Yorkshire with those of Haltwhistle. The latter provided an excellent comparison because it was contiguous with Alston but without lead-mines (Table 1). He concluded that the excessive mortality among the men in Alston and Reeth was associated with lead mining.

TABLE 1

AVERAGE ANNUAL DEATH RATES FOR PULMONARY DISEASE FROM 1848 TO 1854 PER 100,000 FOR AGES $20+$

\begin{tabular}{l|r|c}
\hline & Male & Female \\
\cline { 2 - 3 } Haltwhistle & 374 & 583 \\
Alston & 1,440 & 779 \\
Reeth & 1,298 & 717 \\
\hline
\end{tabular}

The occupational mortality statistics for 1851 were the first of a vast series published by Farr and his successors at the General Register Office. Since Farr's day, the value of death rates as a pointer to occupational hazards has been enhanced by refined occupational groupings. And by recording the mortality rates of the wives of occupied persons, it has been possible to distinguish between occupational and socio-economic hazards.

Many research workers have followed the example of Greenhow in using records of deaths either from the Registrar General's figures or other sources to assess the influence of occupation on health. Within the last 10 years studies of occupational mortality have revealed or confirmed risks of lung cancer in arsenic, asbestos, and gas workers (Bradford Hill and Faning, 1948; Doll, 1952, 1955) and lent support to the hypothesis that physical activity in work protects people from coronary heart disease (Morris and Heady, 1953).

Nevertheless, occupational mortality rates may mislead by indicating non-existent hazards or failing to show important ones. For example, the Registrar General has consistently recorded high cardiovascular-renal death rates for cotton workers exposed to dust. The assertions made on the strength of these rates, that exposure to cotton dust causes hyperpiesis (British Medical Journal, 1947) and that cardiovascular disease was a more serious occupational risk to cotton workers than respiratory disease (Stevenson, 1932), misled me into a field study of heart disease in the Lancashire cotton industry. The apparent excess of cardiovascular deaths is explained by the fact that many of the deaths from respiratory disease have been recorded incorrectly as due to heart disease.*

The Registrar General's data are not sufficiently detailed to indicate other hazards such as the risk of those exposed to benzol and its compounds dying of aplastic anaemia, leukaemia, and liver necrosis, or of dyestuff workers dying of bladder tumours. Nor are these data relevant to the investigation of diseases such as rheumatism and neurotic illness which have high morbidity but low fatality rates.

\section{Sickness Absence}

Many occupational diseases which are not fatal may be revealed by scrutiny of sickness absence rates. Such statistics are beset with the difficulties fully described by Bradford Hill (1955). Sickness absence in industry has to be defined as incapacity to work which is not solely dependent upon a pathological condition, but upon many other factors as well. The nature of the employment is particularly important. A clerk with a fractured wrist can work. A bus driver cannot. The payment of wages during absence has variable effects upon the readiness with which a worker absents himself (Denerley, 1952; Buzzard and Shaw, 1952). The methods of recording sickness vary. Sometimes long absences and short absences are excluded, sometimes not. All these matters must be taken into account in sickness statistics and particularly when contrasting one industry with another, one factory or occupational group with another. Selective recruitment and discharge may be important. Age and sex (and with women, marital status) are known to affect sickness-absence rates very much. With such difficulties of analysis and interpretation, the sicknessabsence statistics kept by industry may be quite useless in assessing the health of various groups of workers. But analyses in which these factors are allowed for have been valuable.

I will give two examples of their recent use by industry and the industrial medical officer. Gregory (1955) found that men in gas works had higher sickness absence rates for bronchitis than men employed in the district as fitters and meter readers. Further enquiry indicated that exposure to dust was a more important factor in the aetiology of their bronchitis than exposure to heat, fumes, and gases.

The contribution to the study of sickness absence of the London Transport Executive (1956) is important because it describes reliable methods of

\footnotetext{
* Before 1939 any cardiovascular disease was selected by the Registrar General as the cause of death in preference to any respiratory disease where both were on the same death certificate.
} 


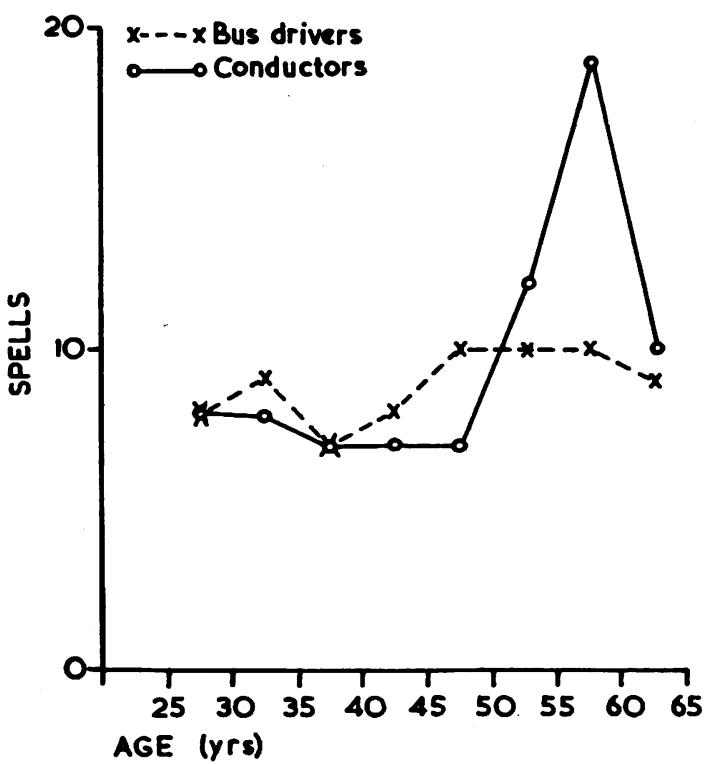

Fig. 1.-Absences (spells) for functional nervous disorder per 1,000 workers per year for central bus drivers and male conductors in London (1949-52).

analysis and gives absence rates for various occupations which, by comparison, may show the effects of different work. Among several interesting comparisons one may be quoted: bus conductors have more sickness absence than drivers, and the differences are most marked for functional nervous disorders in men aged 50-59 (Fig. 1). These figures raise a number of questions. Is the conductor a different type of person from the driver ? Is it more nerve-racking to deal with people who ride on buses in London than with London traffic ? Or is this a phenomenon of the selective discharge of emotionally unstable bus drivers but not of conductors? As drivers are known to have more coronary heart disease than conductors (Morris, Heady, Raffle, Roberts, and Parks, 1953), these figures do not support the notion that nervous strain is an important cause of coronary heart disease.

\section{Treatment Records}

Treatment records in industry are sometimes used to measure occupational health, but they may be an unreliable index of minor accidents and illnesses. Whether or not a worker reports for treatment depends on many things. Some make light of minor ailments. Others make the most of them. Distances from the ambulance room, the personality of the nurse, the possible loss of wages-may all influence the worker's decision to attend for treatment. Williams and Capel (1945) have shown that the proportion of injured factory workers who attend for treatment may vary from $9 \%$ to $25 \%$.

Newbold (1926) found that people who have the most accidents are usually those who pay most visits to the ambulance room for minor ailments. Her results (Fig. 2) have been taken to indicate an association between ill-health and proneness to accidents. But, clearly, recorded minor ailments and injuries and the association between them may be influenced by factors which have nothing to do with health or the hazards of work. Yet it is possible to avoid some of the pitfalls in using these records. Edmonds, Fernandez, and Bates (1954) showed that workers at the coal face suffered much more from boils of the arms and legs than other underground workers and those on the surface (Table 2), and that boils among colliers are an important cause of lost production. When observed with care, the records of minor injuries may reveal departments or particular classes of work in which there is a high risk of injury and thus indicate where preventive action is most needed.

TABLE 2

INCIDENCE OF BOILS PER 100 EMPLOYED IN THREE COALMINES OVER A PERIOD OF TWO YEARS*

\begin{tabular}{l|c|c}
\hline & Head and Neck & Arms and Legs \\
\cline { 2 - 3 } $\begin{array}{l}\text { Coal-face workers } \\
\text { Other underground workers }\end{array}$ & 4 & $13 \cdot 5$ \\
Surface workers & 4 & 5 \\
\hline
\end{tabular}

- Recurrent attacks are not included in these figures.

Field Surveys

Studies of mortality and morbidity rates may only point to occupational hazards and may have to be followed by field surveys in which workers and their environment are examined. The excess of deaths from pulmonary disease which Greenhow found

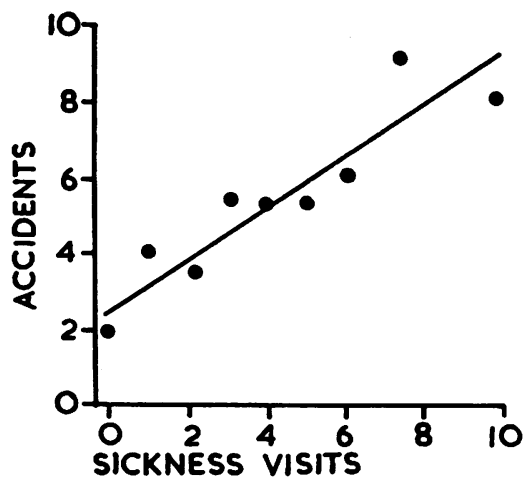

Fig. 2.-Relationship between minor accidents incurred by male workers and sickness visits to the ambulance room (Newbold, 1926). 
in Alston when compared with Haltwhistle pointed to lead mining as the cause. Only clinical and radiological observation of miners could show the extent and nature of the risk. Greenhow (1861) later visited the lead mines to look for causes of the mortality excess in the men of Alston and Reeth. He gave a good clinical description of silicosis, calling the disease "miner's asthma". He also referred to the dangerous dust in the mines driven through sandstone and shale. His work is an excellent example of statistical research leading to clinical and environmental observation. He had no radiographs, no apparatus for measuring dust concentrations, but his field survey confirmed his deductions from mortality statistics.

In field surveys, individuals may be examined clinically, by set questionnaires, or by interview. In this type of work there are difficulties which do not arise in the statistical analysis of mortality and morbidity data. Little or nothing can be done without the cooperation of the population or a sample of it. If a minority refuses to be seen or is unavailable, those who are seen may not be representative of the whole population. In these circumstances, the research will lose much of its value. A low lapse rate is usually achieved only by hard and painstaking preparation in gaining the support of the workers, their unions, and their employers. A research worker who believes that his work is worth while is usually a good advocate, and workmen who think that the investigations are likely to be valuable will invariably cooperate.

Many errors occur in observing clinical signs, in reading radiographs, in taking histories of symptoms, and so on. Much that is recorded may be unreliable and the validity of the observations and answers given to questions has to be tested before the data can be used. If these problems are overcome the field survey can be a valuable instrument of research giving information about the influences of occupation on health which is not obtainable from mortality and morbidity data alone. It is par excellence the method of research for the industrial medical officer. By his clinical contacts with the sick and injured, he has a unique opportunity to spot problems for investigation. And because he " belongs" to the factory or mine or whatever it may be, he should easily secure cooperation. His main difficulty may be that he has to use scientific methods which he is unlikely to have learnt as a medical student. I will give three examples to illustrate the value of the field survey.

Rheumatism and Respiratory Disease in Coalminers.-Coal-miners are known to suffer unduly from rheumatism. Their incapacity rate for rheu- matic complaints has been found to be twice as high as that of other workers (Department of Health for Scotland, 1945). But the nature of these complaints was not well understood until a field survey by Lawrence and Aitken-Swan (1952) showed that in middle age more miners were disabled with pain in the back and knees than non-miners. This led to a more detailed radiological study of miners and controls by Kellgren and Lawrence (1952). They showed that lumbar disk degeneration was the main cause of the disability (Table 3 ).

TABLE 3

RADIOLOGICAL CHANGES IN SPINES OF MINERS AND NON-MINERS AGED 40 TO 49 YEARS

\begin{tabular}{l|c|c}
\hline & Number Seen & $\begin{array}{c}\text { Percentage } \\
\text { with Lumbar Disk } \\
\text { Degeneration }\end{array}$ \\
\cline { 2 - 3 } Miners & 84 & 92 \\
Other manual workers & 45 & 36 \\
Office workers & 42 & 33 \\
\hline
\end{tabular}

Certification rates for coal-miners' pneumoconiosis are sometimes used to indicate the prevalence of this industrial disease. But these rates only show the proportion of men applying for pensions who are considered by the pneumoconiosis panels to be disabled, and do not show latent disease or include the men who are disabled but do not apply for a pension. Cochrane (1951) has demonstrated the enormous difference there may be between certification rates and radiological prevalence of disease. In three pits the ratio varied from $100: 1$ to $6: 1$ (Table 4).

TABLE 4

COAL-MINERS' PNEUMOCONIOSIS RATES PER 1,000 UNDERGROUND WORKERS

\begin{tabular}{l|c|c}
\hline Pit & By Certification & By Radiological Survey \\
\hline A & 97 & 593 \\
B & 2 & 264 \\
C & 14.5 & 295 \\
\hline
\end{tabular}

More recent field surveys of miners have thrown doubts on the value of the radiograph as the sole index of industrial pulmonary disease. In South Wales a significant number of miners compared with non-miners had severe respiratory disability without radiological evidence of pneumoconiosis (Carpenter, Cochrane, Gilson, and Higgins, 1956). In the United States of America, Pemberton (1956) found that chronic bronchitis was much commoner in a community of miners than of non-miners. While this respiratory disability may be the result of industrial pulmonary disease which is not shown radiologically, it may be associated with social influences. In England and Wales miners' wives, who share the same social environment as their husbands, also 
have a mortality excess from bronchitis (Registrar General, 1954). It is only by more detailed field surveys that it should be possible to determine the relative importance of atmospheric pollution at work and away from work as aetiological agents in chronic bronchitis.

Respiratory Disease in Women Cotton Workers.The occupational health problems of women are seldom studied because women are much less exposed to risk than men. But in the Lancashire cotton industry more women than men work in the dusty card rooms. There are no occupational mortality data for them because the Registrar General groups together all women in the textile trades. Bradford Hill (1930), in a study of sickness absence, showed that women card-room workers had a slight excess from respiratory complaints compared with women working in the spinning rooms. Nevertheless, the extent of this risk was not understood until it was shown in a clinical survey of card-room workers that $35 \%$ of some 200 middle-aged women cardroom workers had byssinosis and that those who worked near to the carding engines were most affected (Schilling, Hughes, Dingwall-Fordyce, and Gilson, 1955).

The field survey may be of value in studying diseases which have a relatively high prevalence, but it is less useful when the prevalence is low, as in lung cancer in chromate, asbestos, and arsenic workers, because such large populations have to be seen in order to get conclusive results.

\section{Conclusion}

In a survey of some 3,000 industrial workers, Russell Fraser (1947) showed without much doubt that a high proportion of men and women had suffered from disabling neurotic illness. Anyone with experience of industry knows that mental health and its relationship to work is an important problem in industrial medicine. We see every day what we imagine to be the devastating results of the impersonal atmosphere of the large workshop, of managers and foremen ill-suited for responsibility, of the misfit in the meanest of jobs. But in relating illness to occupational stress neither mortality nor morbidity data are very illuminating, and much surer and simpler methods of assessing neurotic illness need to be devised before field surveys can give valid results (Medical Research Council, 1955). And " health", defined as it has been by the World Health Organization, as physical, mental, and social well-being and not merely the absence of disease, continues to defy reliable assessment.

It seems that we must await the development of better techniques for assessing mental illness and determining its cause, and we must define health in terms that are measurable. Until this is done, the research worker will be inclined to leave " health " and mental illness aside and study disease which can be measured. As he grows older and becomes more aware of the immense difficulties of methodology in occupational health research, he will derive more satisfaction from planning and completing neat and conclusive investigations than from making heroic attempts to achieve unattainable ideals. This feeling towards research has been well expressed by Sir Walter Morley Fletcher (1929), who was Secretary of the Medical Research Council for 20 years:

"If we attempt to measure the value of the scientific life within the community we must put in the first place not the material fruits that spring from it but the service it does to our reverence for truth and for the beauty it portrays."

\section{REFERENCES}

Arnott, W. Melville (1955) Lancet, 2, 783.

British Medical Journal (1947), 1, 728

Buzzard, R. B., and Shaw, W. J.'(1952). British Journal of Industrial Medicine, 9, 282

Carpenter, R. G., Cochrane, A. L., Gilson, J. C., and Higgins, I. T. T.

(1956). Ibid., 13, 166.
Cochrane, A. L. (1951). In The Application of Scientific Methods to Industrial and Service Medicine. Medical Research Council. H.M.S.O., Lond.

Denerley, R. A. (1952). British Journal of Industrial Medicine, 9, 275. Department of Health for Scotland (1945). Chronic Rheumatic Diseases. H.M.S.O., Edinburgh.

Doll, R. (1952). British Journal of Industrial Medicine, 9, 180.

- (1955). Ibid., 12, 81.

and Jones, F. Avery (1951). Spec. Rep. Ser. med. Res. Coun. (Lond.), No. 276

Edmonds, O. P., Fernandez, R. H. P., and Bates, L. B. (1954). British Journal of Industrial Medicine, 11, 123.

Fletcher, W. Morley (1929). Medical Research: The Tree and the Fruit. British Science Guild, London.

Fraser, Russell (1947). Rep. industr. Hlth Res. Board (Lond.), No. 90.
Greenhow, E. (1859). Report of the Medical Officer of the Privy Council for 1858 .

1861). Report of the Medical Officer of the Privy Council for 1860 , App. VI

Gregory, J. (1955). Trans. Ass. industr. med. Offrs, 5, 2.

Hill, A. Bradford (1930). Rep. industr. Hlth Res. Board (Lond.) No. 59.

(1955). British Journal of Industrial Medicine, 12, 333.

$\overline{\mathrm{K}}$, and Faning, E. L. (1948). Ibid., 5, 1.

Kellgren, J. H., and Lawrence, J. S. (1952). Ibid., 9, 197.

Lawrence, J. S and Aitken-Swan, Jean (1952). Ibid, $9,1$.

Legge, T. M. (1934). Industrial Maladies. Oxford University Press,

London.
London Transport Executive (1956). Health in Industry. Butterworth, London.

worth, London.
Medical Research Council (1955). Report for the Year 1953-19ฐ4. H.M.S.O., London.

Morris, J. N., Heady, J. A., Raffle, P. A. B., Roberts, C. G., and Parks, J. W. (1953). Lancet, 2, 1111.

(1953). British Journal of Industrial Medicine, 10, 245

Newbold, E. M. (1926). Industrial Fatigue Research Board. Report No. 34. H.M.S.O., London.

Pemberton, J. (1956). Arch. industr. Hlth, 13, 529

Schilling, R. S. F., Hughes, J. P. W., Dingwall-Fordyce, I., and Gilson, J. C. (1955). British Journal of Industrial Medicine, 12, 217.

Registrar General (1954). Decennial Supplement, England and Wales, 1951. Occupational Mortality, Pt. I. H.M.S.O. London.

(1855). Annual Report for 1851, London.

Stevenson, T. H. C. (1932). Quoted in Report of the Departmental Committee on Dust in Card Rooms in the Cotton Industry [Home Office]. H.M.S.O., London.

Williams, R. E. O., and Capel, E. H. (1945). British Journal of Industrial Medicine, 2, 217 . 